\title{
APLICAÇÃO DE INDICADORES SOCIOECONÔMICOS NOS TERRITÓRIOS DE IDENTIDADE DO SISAL E SEMIÁRIDO NORDESTE II -BAHIA
}

\author{
Philipe Damasceno Pedreira ${ }^{1}$; Jocimara Souza Britto Lobão ${ }^{2}$ \\ 1. Bolsista PIBIC/Fapesb, Graduando em Bacharelado em Geografia, Universidade Estadual de Feira de Santana, e-mail: \\ philipe_pedreira@hotmail.com \\ 2. Orientadora, Departamento de Ciências Humanas e Filosofia, Universidade Estadual de Feira de Santana, e-mail: \\ juci.lobao@gmail.com
}

PALAVRAS-CHAVE: Indicadores socioeconômicos; território; políticas públicas.

\section{INTRODUÇÃO}

O estado da Bahia possui contrastes marcantes nos seus aspectos sociais, econômicos, políticos, ambientais e em geral, nos padrões de uso e ocupação. Nota-se que a articulação destes aspectos, produziram ao longo dos tempos, desigualdades sociais em diferentes regiões no estado. Estas desigualdades são perceptíveis, por exemplo, na concentração de riquezas na Região Metropolitana de Salvador, nos municípios de Feira de Santana, Vitória da Conquista, e alguns municípios da região Oeste, enquanto, em grande porção da região do Semiárido, concentram-se com os piores indicadores socioeconômicos (Bahia, 2007).

Priorizando a redução das desigualdades, adota-se os Territórios de Identidade como estratégia ao desenvolvimento, levando em consideração as peculiaridades políticas, culturais, geoambientais e socioeconômicas de cada território e ainda com o intuito de realizar a descentralização das políticas públicas no estado (BAHIA, 2014) de maneira a ajustar-se às demandas sociais proveniente de cada realidade territorial.

Assim, os estudos das realidades territoriais tornam-se fundamentais para os Territórios de Identidade e uma possibilidade de conhecê-los, configura-se a partir da aplicação de indicadores socioeconômicos, que permitem gerar dados e interpretações, referente as características sociais e econômicas, construindo assim, importantes informações sobre o território.

A utilização dos indicadores socioeconômicos vem ganhando relevância na sociedade, à medida que podem representar e mensurar as várias formas de desenvolvimento, sejam elas de ordem social, econômica e política (SOLIGO, 2012).

Nesse sentido, o presente trabalho, insere-se no contexto da política territorial estadual e federal, tendo como área de estudo o Território de Identidade do Semiárido Nordeste II e o Território do Sisal (Figura 1), instituídos pelo decreto Decreto $\mathrm{n}^{\circ} 12.354$ de 25 de agosto de 2010 - e que objetivou organizar, compreender e sistematizar dados e informações municipais para estabelecer o perfil socioeconômico destes territórios.

Apesar de ter estabelecido o perfil socioeconômico, com variadas informações demográficas (população total, urbana, rural, densidade demográfica); educacionais (matrículas escolares, taxa de analfabetismo, ensino superior e Índice de Desenvolvimento da Educação Básica -IDEB); socioeconômicas (Produto Interno Bruto -PIB, Coeficiente de GINI, Índice de Desenvolvimento Humano Municipal- IDHM) e de infraestrutura de saúde (taxa de mortalidade), dentre outras, aqui atentou-se por apresentar basicamente os aspectos relacionados a participação e dinâmica econômica dos municípios, utilizando o Produto Interno Bruto (PIB) que reflete a produção dos bens e serviços produzidos em termos monetários, o Coeficiente de GINI referente a distribuição de renda e o Índice de Desenvolvimento Humano dos municípios (IDHM). 


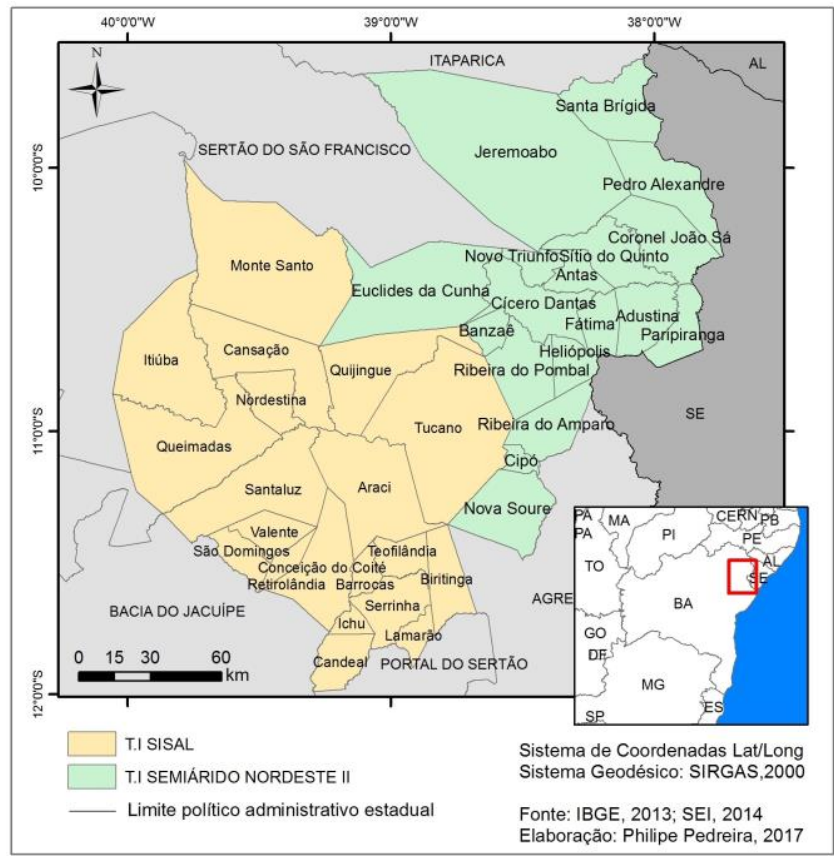

Figura 1: Localização da área de estudo

\section{METODOLOGIA}

Inicialmente, para o desenvolvimento deste trabalho, foi realizado um levantamento bibliográfico que subsidiasse o processo de decisão dos indicadores utilizados. Com isso, foram escolhidos os índices de GINI, IDHM e o PIB para analisar a socioeconomia dos territórios, visando compreender as necessidades de infraestruturas básicas e questões relacionadas a saúde, educação, empregos, longevidade, rendas e desigualdade, visto que, esses indicadores são resultados destes serviços. Os dados aqui utilizados foram consultados em sites de órgãos e instituições que trabalham com as informações socioeconômicas, tais como a Superintendência de Estudo Econômicos e Sociais da Bahia (SEI), Programa das Nações Unidas para o Desenvolvimento (PNUD) e o Instituto Brasileiro de Geografia e Estatística (IBGE). Para análise dos dados foram confeccionados mapas e quadros sistematizando as informações sobre os territórios. Na geração dos mapas foi utilizado software SIG com o intuito de subsidiar a manipulação e organização dos dados.

\section{RESULTADOS E/OU DISCUSSÃO}

O Produto Interno Bruto (PIB) está associado aos setores de agropecuária, indústria e serviços, que abrangem atividades socioeconômicas, como agricultura, pecuária, infraestrutura, transportes, saúde, dentre outras (IBGE, 2013). O PIB no Semiárido Nordeste II no ano de 2014, comporta-se em comparação a participação no PIB do estado da Bahia, em percentual, com os valores de: PIB agropecuário com $2,79 \%$ do total, seguido do setor de serviços com $1,03 \%$ e em menor porção a indústria com $0,49 \%$. O PIB total do território foi de 2.953,99 (R $\$$ milhões), que significa uma parcela pequena comparado ao estado com 223.929,97 (R\$ milhões).

No setor do PIB Agropecuário destaca-se os municípios de Fátima, Euclides da Cunha, Jeremoabo e Paripiranga que no valor adicionado ultrapassaram os 40 (R\$ milhões). Já os municípios de Banzaê, Cipó, Novo Triunfo e Sítio do Quinto representaram os menores valores do território. $\mathrm{O}$ setor industrial é menos representativo que a agropecuária, realça-se apenas Euclides da Cunha e Ribeira do Pombal com PIB de 37,04 e 42,28 (R\$ milhões), respectivamente.

Sobre o PIB agropecuário do Território de Identidade do Sisal também do ano de 2014, que foi de 289,23 (R \$ milhões), denota-se o município de Araci, que possuía o maior valor adicionado de 51,19 (R\$ milhões) e os menores foram Ichu e Lamarão, que juntos 
somavam 5,77 (R \$ milhões). No setor industrial destaca-se o município de Conceição do Coité com 111,58 ( $\mathrm{R} \$$ milhões), quase $24 \%$ do valor total do território. Assim, os setores agropecuários, serviços e indústrias do território representam menos de $2 \%$ cada, de participação total no estado da Bahia.

O Produto Interno Bruto total do Sisal representado na (Figura 2), que demonstra a espacialização no território, destaca-se os municípios de Serrinha e Conceição do Coité com os maiores totais, justificado pelas suas participações nos setores industrias e serviços. E sobre o PIB total do Semiárido Nordeste II (Figura 3) que representa 1,31\% do total da Bahia, ocorre uma variação de 59,65 a 498,18 (R \$ milhões), sendo os municípios de Fátima e Ribeira do Amparo com as maiores participações, o primeiro evidenciado pelo reflexo no setor da agropecuária e o segundo no setor de serviços. A maioria dos municípios (Figura 3) estavam inseridos na classe com os menores valores de PIB total que foi delimitada de 59,65 até 105,35 (R \$ milhões).

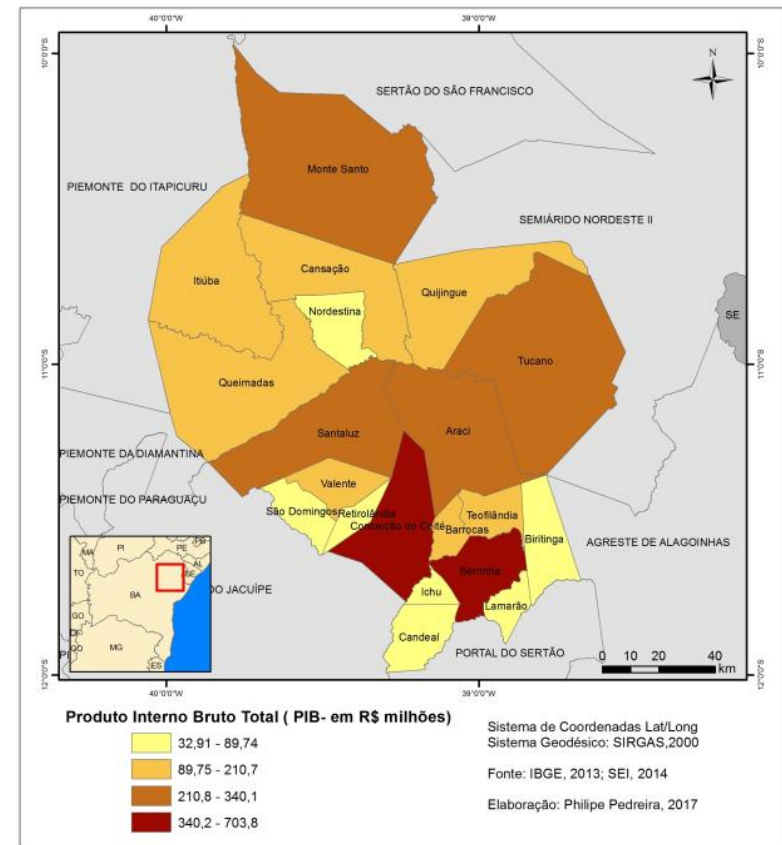

Figura 2: PIB total T.I SISAL

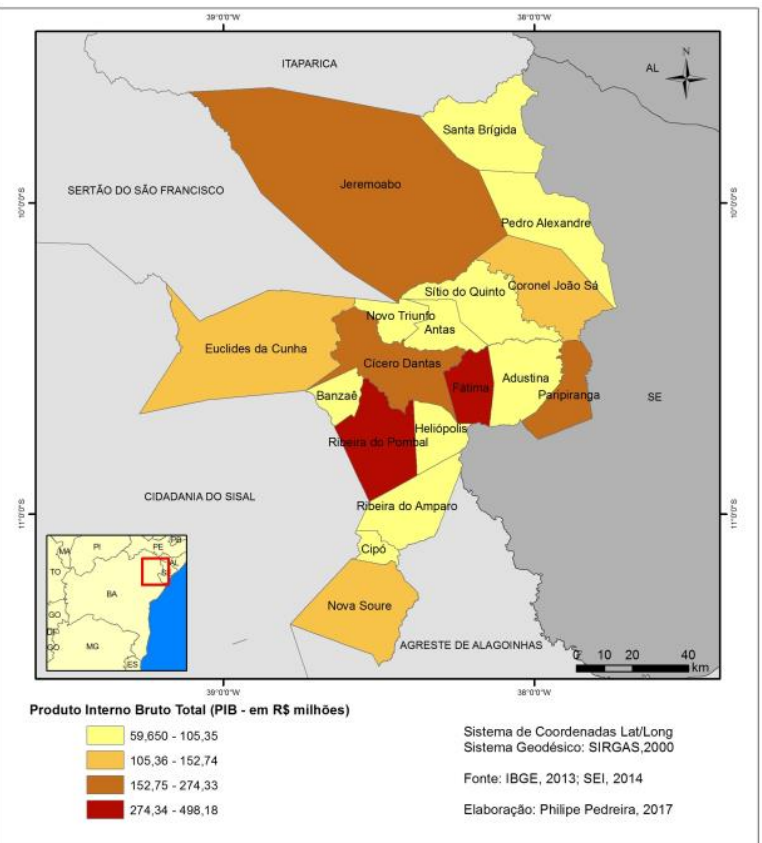

Figura 3: PIB total T.I SEMIÁRIDO NORDESTE II

O índice ou coeficiente de GINI é considerado uma medida estatística para se avaliar distribuição de renda entre determinado grupo (MATOS, 2005; NISHI, 2010). O índice foi elaborado pelo matemático e estatístico italiano Corrado Gini, onde o seu resultado é dado em números entre zero e um, e que zero corresponde à completa igualdade de renda e um à completa desigualdade (Soligo, 2012). Os resultados do GINI no Semiárido Nordeste II, demonstraram que no ano de 2000, o município de Heliópolis apresentava o melhor coeficiente com 0,467 e Jeremoabo a pior distribuição de renda com 0,64. Já no ano de 2010, o município de Antas passou a ter o melhor índice com 0,487 e Paripiranga o menor, porém esse município obteve a maior variação entre os anos em estudo.

O comportamento do coeficiente de GINI no Território do Sisal, foi atribuído sem o município de Barrocas que não possuía dados, logo, leva-se em consideração a presença de 19 municípios, e observa-se que 13 desses, obtiveram em 2010 índices melhores que o primeiro ano em estudo. No ano de 2000, os municípios de Teofilândia, Santaluz, Quijingue, Itiúba e Cansação apresentavam as piores distribuições de renda com o coeficiente de GINI maior ou igual a 0,635 e São Domingos a melhor distribuição com 0,421. Já no ano de 2010, o município de Tucano e Ichu, com GINI de 0,663 e 0,473, respectivamente, representam a pior e melhor distribuição da renda. 
Outro indicador aplicado, refere-se ao IDHM, cuja metodologia, perpassa pela utilização de dados de renda atribuído ao PIB per capita; longevidade com a expectativa de vida ao nascer; educação com índice de analfabetismo e taxa de matrícula nos níveis de ensino (Toni Junior, 2010). A aplicação do Índice de Desenvolvimento Humano nos munícipios do Território de Identidade do Sisal, demonstrou que no ano de 1991, com exceção de Serrinha e Ichu, todos os demais obtiveram valores abaixo da média da Bahia e nenhum valor superior a capital do estado. No ano de 2000, houve uma ampliação nos valores do IDHM, porém nesse momento apenas Ichu com 0,516 ultrapassa a média baiana, mesmo com resultado classificado como baixo (0,500 - 0,599), e o município de Monte Santo continha o menor valor. No ano de 2010 , todos os municípios possuíam valores classificados como médios (0,600- 0,699), enquanto a média da Bahia era de 0,660, a qual nenhum município atingiu, porém, destaca-se os resultados dos municípios de Retirolândia e Serrinha que ultrapassaram nesse ano a pontuação de Ichu. Os municípios de Lamarão e novamente Monte Santo possuíam os menores valores do território.

No território do Semiárido Nordeste II, os municípios de Santa Brígida, Ribeira do Amparo, Pedro Alexandre e Coronel João Sá em 1991 obtinham pontuações abaixo de 0,200, significando menos da metade do IDHM de Salvador que detinha 0,563. No ano de 2000, enquanto a média baiana era de 0,512 e classificada como baixa, nenhum município do território atingiu este valor e todos ainda foram classificados com IDHM muito baixo, ou seja, menor que 0,499. Nesse mesmo ano, Antas, Cipó e Ribeira do Pombal possuíam os maiores índices. Os municípios de Pedro Alexandre e Ribeira do Amparo tornaram a apresentar, porém no ano de 2010, os menores IDHM e destaca-se positivamente Cipó e Ribeira do Pombal com 0,601, enquanto a média baiana representava 0,660 .

\section{CONSIDERAÇÕES FINAIS}

Pôde-se constatar por meio dos indicadores utilizados que na sua totalidade os territórios precisam de incremento da renda, programas sociais e empregos que subsidiem e movimentem a economia dos municípios de modo a combater a concentração de renda e consequentemente ocorra uma melhor distribuição de renda nos territórios.

Observa-se que na série histórica os municípios de Araci, Lamarão e Monte Santo no território do Sisal e Pedro Alexandre e Ribeira do Amparo no território do Semiárido Nordeste II apresentam os menores IDHM, percebendo a necessidade da melhoria das condições de vida dessas populações, por meio dos aspectos relacionados ao aperfeiçoamento da educação com progressos na taxa alfabetização e ensino básico, na longevidade com melhoria dos níveis de mortalidade e qualidade de saúde. Em geral, deve-se estruturar políticas públicas específicas para cada realidade municipal dos territórios.

\section{REFERÊNCIAS}

BAHIA. 2007. Secretaria do Planejamento. Plano Plurianual 2008-2011. Salvador. . 2014. Bahia, 2000-2013. São Paulo: Editora Fundação Perseu Abramo.

IBGE. 2013. INSTITUTO BRASILEIRO DE GEOGRAFIA E ESTATÍSTICA. Contas Nacionais, número 41. Produto interno bruto dos municípios. Rio de Janeiro.

MATOS, J. 2005. Distribuição de renda: fatores condicionantes e comparações entre regiões metropolitanas pesquisadas pela PED. Porto Alegre: FEE.

NISHI, L. F. 2010. Coeficiente de Gini: uma medida de distribuição de renda. Florianópolis: Universidade do Estado de Santa Catarina.

SOLIGO, V. 2012. Indicadores: conceito e complexidade do mensurar em estudos de fenômenos sociais. Est. Aval. Educ., São Paulo.

TONI JUNIOR, C. N. 2010. Análise do IDH do Brasil, de suas regiões e de outros países: Um enfoque comparativo. 164 f. Dissertação (Mestrado) - Curso de Engenharia de Produção, Universidade Federal de São Carlos. 